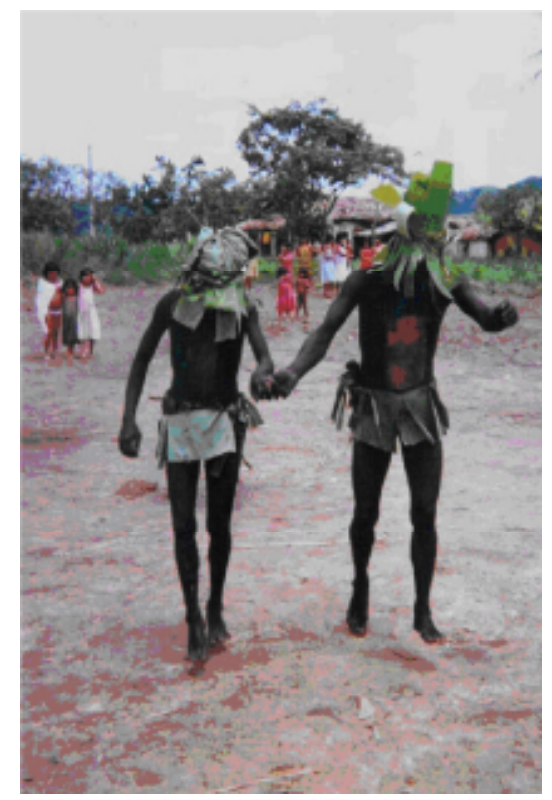

Charles Bicalho

\title{
Yãmîys maxakali - iconotextos indígenas
}

\section{Charles Bicalho}

Doutorando em Literatura Brasileira, Universidade Federal de Minas Gerais Professor de Língua Portuguesa (Leitura e Escrita) no Curso de Formação de Professores Indígenas de Minas Gerais.

\section{Resumo}

Este artigo trata das conexões e interações entre o verbo e a imagem no âmbito da tradição indígena maxakali, especificamente os cantos rituais - yãmîys - recitados nas cerimônias yãmîyxops. Aborda os yãmîys na perspectiva de um gênero poético performático e apresenta a transcriação, nos termos da teoria de Haroldo de Campos, como opção de modelo tradutório para esses textos. Paralelamente, sugere uma configuração paratática ou ideogrâmica dos yãmîys, considerando-os como iconotextos dos entes totêmicos do universo indígena.

Palavras-chave: Yãmîy, Maxakali, iconotextos. 


\section{Introdução}

O iconotexto, esta zona onde o texto se põe a sonhar com a imagem. Louvel

No princípio era o verbo... e a imagem. "A escrita nasceu da imagem $e$, seja qual for o sistema escolhido, o do ideograma ou - do alfabeto, sua eficácia procede unicamente dela", escreve Anne-Marie Christin em $A$ imagem escrita ou a des-razão gráfica.(1) De fato, na escrita cuneiforme (impressa na argila e tendo três dimensões: altura, largura e profundidade), em sua fase pictográfica, o que mais tarde viria a ser letra é a representação metonímica do gado: a letra "A" surge da representação pictórica da cabeça do boi. Talvez haja mais afinidades entre o gesto da mão sobre o papel com a caneta e o lápis, ao escrever, e o gesto da mesma mão com o pincel sobre a tela, ao pintar ou desenhar (também entre a mão com - mouse e o cursor na tela do computador), do que sonham nossas vãs teorias. Exemplos dessa imbricação genética são os trabalhos artísticos de caligrafia árabe ou chinesa. Esta, magistralmente ilustrada no filme o livro de cabeceira, de Peter Greenaway. Portanto, no princípio era o signo, em todas as suas variações e possibilidades.

Esse pode ser 0 ponto de partida para tentarmos entender porque os primeiros índios à época do contato pós-descoberta ficaram tão fascinados em ver a mão européia a desenhar sinais engraçados no papel (a ponto de chegar a imitar a escrita, no gesto, criando rabiscos). E talvez, isso explique tanto o fato de hoje em dia um povo como os Maxakali abraçar tão visceralmente a escrita, já tendo incorporada à sua tradição essa modalidade de registro desde a década de 1960, quando missionários os alfabetizaram e tentaram catequizá-los (sem sucesso), quanto o fato de essa escrita ser usada até hoje, como um reconhecimento de sua utilidade. Provavelmente os Maxakali perceberam que

a escrita oferece a uma sociedade a possibilidade de ampliar seu campo de comunicação verbal para além das fronteiras de sua própria língua. Nenhum outro motivo além desse poderia forçar os homens a adaptar as estruturas de uma linguagem, da qual dependiam não apenas sua posição social, mas também seu universo de pensamento, às estruturas de um medium cuja aura, por outro lado, o aproximava sobremaneira das práticas obscuras e incontroláveis da magia. (2)

Talvez, isso também explique porque esses mesmos indivíduos não viram nenhum problema em adotar a tecnologia do computador (que agrega indistinta e anti-hierarquicamente a escrita, a 
imagem, o som e outras mídias) em seu processo de aprendizagem, manutenção e divulgação de seu conhecimento e tradição.

\section{Maxakali, Yãmîy, Yãmîyxop}

Os Maxakali vivem no nordeste de Minas Gerais, precisamente no Vale do Mucuri. Segundo os lingüistas, sua língua pertence à homônima família Maxakali que, por sua vez, pertence ao tronco Macro-Jê. O Macro-Jê e o Tupi são os dois principais troncos lingüísticos indígenas do Brasil. Os Maxakali surpreendem por ainda manter intacta não só sua língua, mas quase toda a sua cultura, incluindo a religião, a organização social, os costumes etc.

Yãmîy quer dizer "canto" em maxakali. E também "espírito". Yãmîy é a concepção central para se entender a cultura maxakali. Mais especificamente, os yãmîys são cantos sagrados, verdadeiras composições poético-musicais (poemúsicas) cantadas nos yãmîyxops, rituais sagrados. Osyãmîys-cantos referem-se aos yãmîys-espíritos. Ou seja, para cada divindade maxakali há pelo menos um canto correspondente. Tais divindades incluem animais terrestres, pássaros, insetos e figuras míticas da tradição indígena. Yãmîy então é uma palavra maxakali que designa os espíritos de seu panteão. E designa também os cantos relacionados aos espíritos.

Os yãmîys são cantados principalmente nos yãmîyxops. Osyãmîyxops são as cerimônias, rituais em que os humanos interagem com os espíritos. Xop em maxakali tem a noção de grupo, plural. Um yãmîyxop é uma reunião de yãmîys, de espíritos. Trata-se de uma grande festa em que, para que aconteça o contato entre o mundo dos vivos e o mundo dos mortos (semelhante ao contato entre vivos e mortos na tradição literária), são usados todos os recursos e as artes da performance. Os yãmîyxops envolvem toda a comunidade de uma aldeia. São realizados para agradecer aos espíritos por uma boa colheita, ou para pedi-la. São realizados também para pedir a cura de um doente. Durante todo o dia que precede a noite do ritual todos os membros da comunidade de uma aldeia ficam envolvidos com os preparativos do yãmîyxop.

Nas performances do yãmîyxop maxakali, a imagem, o verbo, o corpo, o alimento, a música, o contato, em suma, todos os sentidos, em todos os sentidos, são importantes. A exploração de todas as sensações do corpo é importante para se alcançar a transcendência. Nelas se canta uma variedade de yãmîys incessantemente. 
Para JAKOBSON, "O ritual costumeiramente combina a fala e componentes pantonímicos e, como notou Leach, ocorrem nessas usanças cerimoniais certas espécies de informação que jamais são verbalizadas por seus executantes, mas apenas expressas na ação." E, continua ele, "esta tradição semiótica é, contudo, sempre dependente, pelo menos de um padrão verbal emoldurante que passa entre as gerações"(3). São os yãmîys(e também suas narrativas correspondentes) que, no caso Maxakali, cumprem o papel deste "padrão verbal emoldurante".

Neste artigo vamos explorar como o verbo e a imagem desempenham seus papéis, imbricando-se, e como essas duas expressões simbólicas podem estar emaranhadas na produção de sentido em um ritual yãmîyxop. E qual é a derivação disso na produção de material didático e literário nos cursos de educação e escolas indígenas.

\section{Da oralidade à escrita}

A escrita foi introduzida na língua maxakali por Harold Popovich, missionário do Summer Institute of Linguistics(SIL), órgão norte-americano que patrocina catequeses mundo afora. Popovich conviveu com os Maxakali na década de 60, aprendeu sua língua, introduziu a escrita e alfabetizou alguns índios.

A Constituição Brasileira, em seu artigo 210, parágrafo segundo, dispõe que: "O ensino fundamental regular será ministrado em língua portuguesa, assegurada às comunidades indígenas também a utilização de suas línguas maternas e processos próprios de aprendizagem." E no artigo 231: "São reconhecidos aos índios sua organização social, costumes, línguas, crenças e tradições, e os direitos originários sobre as terras que tradicionalmente ocupam, competindo à União demarcá-las, proteger e fazer respeitar todos os seus bens." Com base nisso tiveram início em todo o Brasil programas de educação diferenciada para os povos indígenas. Em Minas, criou-se o Programa de Implantação de Escolas Indígenas de Minas Gerais (PIEI-MG). Uma parte do Programa objetiva elaborar - material didático a ser usado pelos índios em suas escolas: cartilhas de alfabetização, livros de Geografia, Matemática, História e, naturalmente, obras literárias. Essa produção, no caso maxakali, costuma ser bilíngüe. E sua literatura, antes exclusivamente oral, agora surge em livros. É assim que vemos nascer um novo e rico acervo literário a ser consumido também pela sociedade que o envolve. "O produto final", revela Maria Inês, "aponta para um modelo de texto cuja leitura demandaria antes os cinco sentidos do corpo, ao invés de um modelo logocêntrico, racional".(4) 


\section{Yãmîy como um gênero performático}

Yãmîy é poesia no estilo das melhores performances. Umyãmîyxop é um espetáculo que apela aos cinco sentidos. Nas aldeias, canto, dança, poesia e teatro são indissociáveis em rituais de cura ou de ciclos anuais (5). Num yãmîyxop ouvemse yãmîys incessantemente. Eles são cantados no centro da aldeia por homens e mulheres.

No aspecto visual, o figurino não é menos importante. Cada yãmîy tem sua indumentária, suas cores e formas de pintura, que enfeitam o corpo daqueles que encenam.

O tato acontece no contato físico entre os participantes. Há momentos na dança em que se formam grandes círculos em que todos giram abraçados.

- paladar também é aguçado, pois faz parte dos rituais a ingestão de bebida, principalmente café e cachaça (sabe-se que tradicionalmente os Maxakali ingeriam um certo chá que caiu em desuso ao longo do tempo e foi substituído por essas bebidas) e comida. O alimento costuma ser servido em caprichados pratos com xuinãg ("arroz"), vezes pêyôg("feijão"), xokkakak ("frango") ou carne de xapup ("porco") ou mûnûy ("boi") e mãkãhãm ("macarrão"). Se houver, também se serve kômîy ("batata"), kohot ("mandioca") e paxok("milho"). A comida é uma oferenda aos yãmiys, que se satisfazem comendo dentro da kuxex, a "casa de religião".

o olfato, nas aldeias, é estimulado pelo cheiro do mato, da terra, do corpo e da fumaça, principalmente. Há muita fumaça (kuho - "corrô") impregnando os objetos e as pessoas, seja pelo fato de que, recolhidos ao lar, os Maxakali acendem fogueiras praticamente dentro de casa, o que acaba por defumar a tudo e a todos (é característico o cheirinho de fumaça que impregna os objetos maxakalis, principalmente, seu artesanato), seja pelos cigarros fumados durante osyãmiyxops. A fumaça é sagrada para os Maxakali. É considerada o alimento dos espiritos. Por isso se fuma bastante, tanto nos rituais, quanto no dia-a-dia. Fuma-se tanto o kohomanîy ("cigarro preto", que é o cigarro não-industrializado, de palha ou enrolado em papel) quanto okohopodo ("cigarro branco", o cigarro industrializado). Kohosignifica "fumaça" e, metonimicamente, "cigarro". Manîy("manin"), como já se percebeu, é "preto", e podo ("pôdô"), "branco".

A poesia yãmîy, com todo seu aparato performático, apelando aos cinco sentidos do corpo, propicia um verdadeiro e visceral desregramento de todos os sentidos. 
Nas publicações, procura-se preservar pelo menos o mínimo de tal estatuto. O Livro de cantos rituais maxakali(6), por exemplo, além da escrita e da tradução de alguns yãmîys, traz encartado um CD, gravado nas aldeias de Pradinho e Água Boa, contendo três yãmîys cantados pelos índios.

\section{Transcriando Yãmîy - o espírito e a coisa}

José Paulo paes afirma quanto ao fato de não falar nem ouvir, mas apenas de traduzir 10 dos 12 idiomas que domina: "sou surdo e mudo em 10 línguas". Eu sou surdo e mudo em Maxakali. Não falo nem entendo uma conversação maxakali, mas o que aprendi da língua nos mais de dez anos de contato com ela, com muita troca e aprendizado, permite-me traduzir, em colaboração com os índios, seus textos e, no caso da poesia, buscar uma transcriação.

Nesse processo, primeiramente são elaboradas versões prosaicas traduzidas palavra por palavra, em colaboração com os índios, na reserva ou em qualquer outro lugar onde se dêem nossos encontros. Depois, com calma, busca-se a reprodução dos sons, a musicalidade dos versos, um certo ritmo. Tenta-se também criar algumas imagens que se compatibilizem com a profusão metafórica natural da língua indígena e outros elementos que fazem de um texto um texto poético.

A transcriação de poesia é a tentativa, como escreve Haroldo de Campos, de captar o "espírito" do texto poético. Em suas palavras, trata-se de "ser fiel ao 'espírito', ao 'clima' particular da peça traduzida"(7):

Numa tradução dessa natureza, não se traduz apenas o significado, traduz-se o próprio signo, ou seja, sua fisicalidade, sua materialidade mesma (propriedades sonoras, imagética, enfim tudo aquilo que forma, segundo Charles Morris, a iconicidade do signo estético, entendido por signo icônico aquele "que é de certa maneira similar àquilo que ele denota"). o significado, o parâmetro semântico, será apenas e tão somente a baliza demarcatória do lugar da empresa recriadora. Está-se pois no avesso da chamada tradução literal(8).

Assim, o que se pretende, no caso de yãmîys, é se deixar cair na tentação de captar ou capturar o "espirito da coisa" no texto maxakali, sendo o espírito o significado e a coisa - o significante, para usarmos da terminologia semiótica. Aqui não é o símbolo que determina, mas o ícone que indetermina.

Vamos a um exemplo. O yãmîy seguinte foi registrado por Sandro Campos, lingüista da UFMG que pesquisa a língua maxakali. 


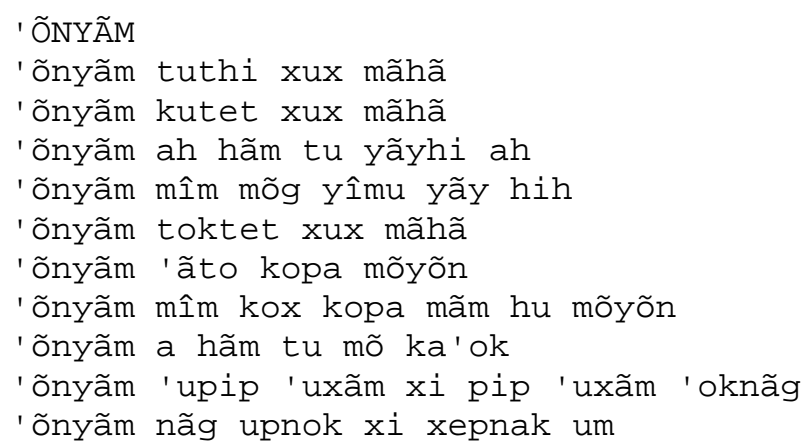

Numa tradução prosaica temos:

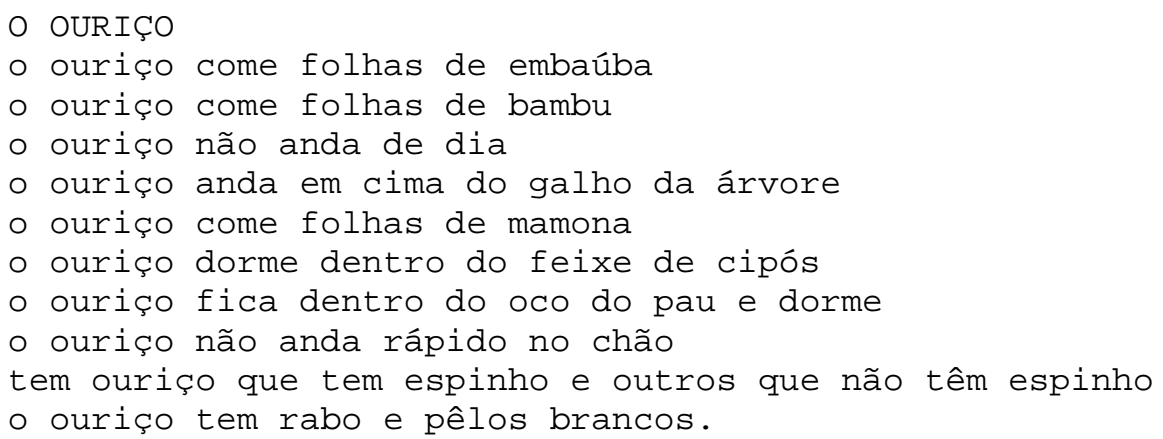

Se se persegue a poeticidade inerente a praticamente todo texto maxakali, e especialmente aos yãmîys, pode-se elaborar algo um pouco diferente.

Vejamos. Não há o que fazer nos três primeiros versos. Já há, inclusive, uma assonância espontânea entre "embaúba" e "bambu" e o ddd de "anda de dia" do terceiro verso não é mal. No quarto verso, podemos sintetizar "anda em cima do galho da árvore" em "caminha no galho da árvore", em que os dígrafos $n h$ e lh reverberam-se. O sexto verso, traduzido por "dorme dentro do feixe de cipós" (Sandro explica que 'âto em Maxakali designa "feixe de cipós cujo interior é usado pelo ouriço como abrigo"), pode ser adaptado para "dorme num ninho de cipós", onde as consoantes nasalizantes $m$ e $n$, duplicadas, mais o nh amaciam sonoramente o leito do ouriço. "No oco do toco", do sétimo verso, reproduz a aliteração dok no verso original, kox kopa, literalmente "dentro do buraco ou oco". Na língua maxakali, kox aparece, por exemplo, na composição de konãgkox, vocábulo para "rio", que é a junção de konãg ("água") + kox ("buraco"). Ou seja, "um oco ou buraco onde corre a água". Sonora e visualmente, a palavra "toco" acolhe literalmente o "oco" dentro de si. O oitavo verso tenta se comparar, pela aliteração dos ss, em "vai suave sobre o solo", ao original, também com aliteração, só que em $m$. O verso seguinte mantém a repetiçãopip 'uxãm xi pip 'uxãm oknãg, que literalmente em maxakali quer dizer "tem espinho e tem espinho pequeno" (oknãg quer dizer pequeno, diminuto), mas apresenta um verso mais sintético e harmonioso: "com espinho e sem espinho". Por fim, o último verso traduz o quase anagrama do 
original, entre upnok xi xepnak (xi em maxakali é a conjunção e), em uma rima assonante interna: "rabo" com "claro". Sendo assim, temos a transcriação:

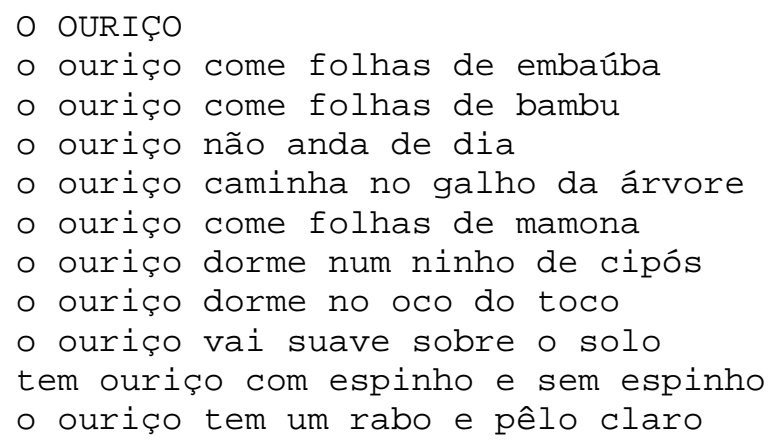

\section{Ideogramaxacali ou a montagem artística do Yãmîy}

Antônio Risério, em seu Oriki Orixá, coloca o oriki, gênero de poesia oral africana, ao lado de outros, como o haicaijaponês e o soneto ocidental. A diferença é que o oriki não é um gênero de forma fixa como o soneto, por exemplo, que exige determinado número e tipo de estrofe e rima para ser considerado um exemplar. Ou ainda o haicai que também, pelo menos em sua origem no Japão, é estritamente composto por três versos cuja métrica é 5-7-5 sílabas poéticas, respectivamente. Paul Zumthor, no entanto, diz que "só excepcionalmente uma forma é estável e fixa; ela comporta uma mobilidade proveniente de uma energia que lhe é própria"(9). De fato, o próprio haicai, ao ganhar o mundo, abandonou sua forma fixa. Sabe-se que valores como síntese, imagética, ou sua candidez natural são valores tão ou mais intrínsecos.

O oriki é também um canto a um espírito. No caso, a um espírito africano: o orixá. Segundo Risério, citando oDicionário de cultos afro-brasileiros, de Cacciatore, tratase de um "cântico de louvor que conta os atributos e feitos de um orixá" (10). Risério explica: ele não é oração, mas uma "figuração paratática do orixá". Entende-se a parataxe por oposição à hipotaxe:

a parataxe é a organização por coordenação, e o seu pivô é o conjunto das chamadas conjunções coordenativas; a hipotaxe é a organização por subordinação, que se articula graças às conjunções subordinativas. (11).

Paratático, portanto, é o oriki, - e, segundo nossa hipótese, também o yãmîy - no sentido de que o discurso que o estrutura prescinde de conectores lógicos, como as conjunções, e não se organiza em períodos compostos por subordinação, o que dá à fala ou à escrita um caráter hierarquizante, como normalmente acontece no discurso ocidental. 
Vemos que o poema maxakali do ouriço, aqui transcriado, não apresenta "frases que se montam por subordinação hierárquica" numa "seqüência de causas e efeitos". Ele se mostra muito mais como um texto em que "as frases estão em pé de igualdade", sem orações subordinadas, numa estrutura em que as frases "podem ser justapostas e encaixadas ad infinitum"(12). Cada verso se coloca como uma idéia ou imagem completa, sem conectores que os concatenem. Cada verso é uma frase completa. O paralelismo que há no poema, principalmente pela repetição do sintagma "o ouriço" a iniciar cada um dos versos reforça tal concepção.

Analisando o mesmo procedimento presente no oriki, Risério diz: "O oriki é sobretudo uma espécie de montagem de atributos do objeto que tematiza. Uma construção epitético-ideogramática. O que importa é isso: montagem de atributos, colagem de predicados, justaposição de particularidades e emblemas". E mais: "O método de montagem. Um oriki de Omolu, por exemplo, é uma espécie de ideograma do senhor das pestes".(13).

Montagem, ideograma, eis o princípio que rege também o yãmîymaxakali. Eisenstein, em seu famoso estudo "o princípio cinematográfico e o ideograma", analisando o haicai e otanca (este é um gênero mais antigo que derivou aquele), vai dizer: "Ambos são pouco mais que hieróglifos transformados em frases. Tanto que metade de sua qualidade é avaliada por sua caligrafia.(14). O método de resolução de ambos é inteiramente análogo à estrutura do ideograma" (15). Tal concepção é muito próxima do que se pode inferir do método ideogrâmico de Pound, assim definido por Géfin:

a process where the artist, by precise perceptions, attains a vision of the relationships between the particulars observed and the working of nature. From the exactness of these perceptions the artist recreates this vision in the literary work; and from this, acute and attentive readers may attain their own vision or revelation (...) The artist seeks out the luminous detail and presents it. He does not comment (16).

"Do nosso ponto de vista, estas são frases de montagem. Séries de tomadas"(17), acrescenta Eisenstein sobre o haicai. É como se cada verso fosse a tomada de uma cena num filme. Entre um e outro há um corte. Como se cada verso fosse um fotograma. Ou, como diz Modesto Carone em seu estudo sobre a poesia de Georg Trakl, "as imagens isoladas do poema se comportam como as 'tomadas' ou os fotogramas montados num filme"(18) • O mesmo se dá no caso dos poemas maxakalis: cada verso pode ser visto como a tomada de uma cena, como se o poema fosse um roteiro sintético. Vejamos o exemplo da "Canção do martin-pescador pequeno". 


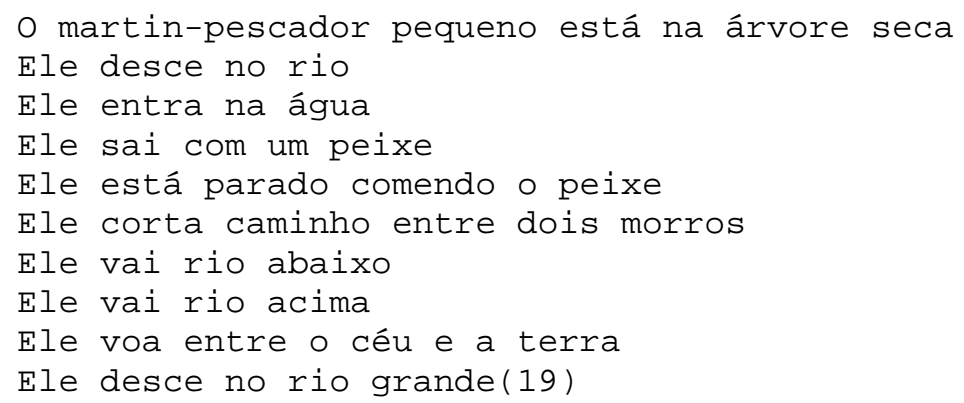

Em associação com os desenhos, tem-se, através dos versos, praticamente um storyboard! Com o livro maxakali em mãos, essa sensação é ainda mais nítida. Os yãmîys são uma espécie de avatar que concretiza a presença de um espírito através do método da montagem ou do ideograma.

\section{Toteogramas/iconotextos}

A lógica que rege o yãmîy maxakali é a do totem. Um clã se identifica com as características de determinado animal e sua vida espiritual gira em torno disso. Freud, em "Totem e tabu", dá uma explicação cabal do termo:

Via de regra é um animal (comível e inofensivo, ou perigoso e temido) e mais raramente um vegetal ou um fenômeno natural (como a chuva ou a água), que mantém relação peculiar com todo - clã. Em primeiro lugar, o totem é o antepassado comum do clã; ao mesmo tempo, é o seu espírito guardião e auxiliar, que lhe envia oráculos, e embora perigoso para os outros, reconhece e poupa os seus próprios filhos. Em compensação, os integrantes do clã estão na obrigação sagrada (sujeita a sanções automáticas) de não matar nem destruir seu totem e evitar comer sua carne (ou tirar proveito dele de outras maneiras). O caráter totêmico é inerente não apenas a algum animal ou entidade individual, mas a todos os indivíduos de uma determinada classe. De tempos em tempos, celebram-se festivais em que os integrantes do clã representam ou imitam os movimentos e atributos de seu totem em danças cerimoniais(20)

A despeito de toda a questão em torno da "ilusão totêmica" levantada por Lévi-Strauss em Totemismo hoje em dia(21), uso a idéia de "totemismo" para designar a idéia básica que ele representa. Sendo assim, não pretendo entrar no mérito da questão totêmica mas usar a definição de totemismo mais geral, como se coloca na Enciclopédia Einaudi: "totemismo conota simplesmente a idéia de uma associação entre uma espécie animal (ou outra) e uma parte da sociedade, quer se trate de um grupo ou de um (ou mais) indivíduo(s)"(22). 
Popovich reconheceu que os seres sobrenaturais ("supernatural beings") maxakalis e seus rituais se baseiam na idéia do yãmîy, termo que, de acordo com ele, pode ser traduzido como "alma dos mortos": "Yãmîyxop consists mostly of souls of dead Maxakali, and a few souls of Indians of other tribes, national Brasilians, and animals" (23). Ele reconhece 10 grandes grupos de yãmîy, os quais se constituem de mais de 200 subgrupos (24). Dentre os 10 grupos encontram-se por exemplo o da anta (ãmãxuxxop), o das folhas (mîxuxxop), o do papagaio (putuxop), - do morcego (xûnînxop), o do kotkuphi (palavra que designa o talo da mandioca) etc. Nos subgrupos encontram-se a própria anta, a capivara (kuxakkuk), o abacaxi (kutitta), a cachoeira (kukmok), o veado (mûnûy), a vaca (mûnûytut), a onça (hãmgãy), - caititu (xapupnãg), a jaguatirica (xokãnêhnãg), a abelha (kutapax), a cigarra (patakak), a grama (mîxux kupnãg), o bambu (tatakox), a arara (putuxop xexka) etc.(25).

Popovich, no entanto, resolve não utilizar o termo "totem" em relação aos Maxakali, porque, segundo ele, "even though these groups are societies consisting of certain dead and living going by various names, they do not divide the tribe into distinct societies"(26).

O fato é que não há um estudo específico e significativo sobre a questão do totem junto aos Maxakali. Em entrevistas com os índios, no entanto, pude comprovar que Izael Maxakali e sua família, por exemplo, pertencem ao grupo ou clã da chuva (texxop). Ele mesmo me revelou ainda que, para casar, é necessário que a moça venha de um grupo ou clã diferente do seu. $O$ que nos faz crer que os yãmîys interfeririam na organização social dos Maxakali. Contudo, a questão fica em aberto...

Ainda que, como escreve Freud, "muitos investigadores tendem, assim, a [encarar o totem] como uma fase necessária do desenvolvimento humano que tem sido universalmente atravessada" (27), podemos pensar que, mesmo nas sociedades não-indígenas, ainda encontramos seus resquícios em metáforas do tipo "ele está uma fera", "ele virou um leão", "ela é uma flor" etc., em que reconhecemos, assim como no totemismo, afinidades entre os humanos e outros seres da natureza. Daí se pode pressupor uma relação ancestral entre 0 totem $e a$ metáfora.

A formação de uma imagem ou diagrama é cara ao totemismo. Numa explicação sobre a origem do totemismo, Freud apresenta três teorias. Numa delas, a Teoria Nominalista, o psicanalista cita Keane, que encara os totens como 'insignias heráldicas', por meio das quais os indivíduos, as famílias e os clãs procuravam distinguir-se uns dos outros"(28). Daí, a idéia de um ícone simbolizando um clã, como nos brasões de família, e 
modernamente as logomarcas de empresas, ou as bandeiras dos países, ou ainda os brasões de times de futebol. Trata-se da idéia de uma marca associada a uma organização. E, como escreve Haroldo,

a noção peirciana de 'diagrama' permite trasladar ('traduzir'), para o âmbito das línguas fonético-alfabéticas (ou da poética dessas línguas, onde o lado palpável do signo assume o primeiro plano), a concepção fenollosiana (e poundiana) do ideograma e do método ideogrâmico de compor (sintaxe relacional, paralelística, paratática). (29)

O fato é que tal imagem ou ícone totêmico pode se formar através das palavras. É o caso do que estamos denominandototeogramas (cantos que pressupõem uma composição escritural - poemúsicas - como espécies de mantras, relacionados aos entes totêmicos). Conforme Haroldo de Campos, "a poesia e a arte das 'mantras' são aproximadas da música, pela importância que todas dão a esse aspecto 'configuracional' (ou 'diagramático', como o chamaria Jakobson, reportando-se conjuntamente a Peirce e a Whorf)"(30).

Assim é que, partindo da expressão cunhada por Décio Pignatari em ensaio sobre a tradução da obra de Marina Tsvietáieva (que ele considera uma "tentativa de estruturar uma montagem gestáltica da poesia"), qual seja, um "diagrama totêmico" (31), resolvemos criar o neologismo "toteograma", mais sintético e mais ideogrâmico, para os poemas indígenas que apresentam através da palavra os entes totêmicos do universo cultural indígena. Sendo assim, podemos observar osyãmiys maxakalis como poemas toteogrâmicos, verdadeiras escrituras do totem, ou avatares escriturais do totem. Tem-se um iconotexto quando se dá a "presença de uma imagem visual convocada pelo texto"(32). Citando Julius Pikler em seu estudo, Freud escreve:

A humanidade exigiu, tanto das comunidades quanto dos indivíduos, um nome permanente que pudesse ser fixado pela escrita (...) Assim, o totemismo não surgiu das necessidades religiosas dos homens, mas de suas necessidades práticas e cotidianas. O âmago do totemismo, sua nomenclatura, é o resultado da técnica primitiva de escrita (grifo meu). Em sua natureza, um totem assemelha-se a um pictograma facilmente desenhável (grifo meu). Entretanto, uma vez portadores do nome de um animal, os selvagens passaram a formar a idéia de um parentesco com ela.(33).

Ou seja, o totemismo parece funcionar como uma modalidade "primitiva" da concepção de grama, inscrição, escritura ou registro, o que Pikler está chamando de pictograma, em termos imagéticos. Na concepção semiótica peirciana, trata-se da formação de um signo icônico. Este grama - chamemo-lo assim pode ser formado como um desenho (imagem) ou uma palavra: 
ícone ou símbolo. No caso dos yãmîys, eles são palavras cantadas. Em outros termos: são símbolos com forte tendência icônica.

Sendo assim, os yãmîys apresentam os animais totêmicos, seres espirituais, através da palavra, mostrando-nos seus atributos e suas características, no intuito de fazer surgir sua imagem. Tudo isso se dá em termos paratáticos, donde se pode reconhecer os yãmîys como textos icônicos (ou iconotextos). Se "a performance é a ação complexa pela qual uma mensagem poética é simultaneamente, aqui e agora, transmitida e percebida"(34) deve-se reservar um lugar para o yãmîy maxakali no aqui e agora da poesia.

\section{Abstract}

This article is about conections and interactions between word and image in the maxakali indigenous tradition, more specifically the songpoems yãmîy, declaimed in the yãmîyxops ritual cerimonies. It assumes the yãmîy as a performatic poetic gender and presents the "transcriation", in terms of Haroldo de Campos' theory, as an option of translation model of this kind of text. Besides that, it suggests a paratatic or ideogramic configuration of yãmîys, considering them as iconotexts of the totemic entities of the indigenous universe.

Keywords: Yãmîy, Maxakali, iconotexts.

\section{Notas}

[1] ARBEX, 2006. p. 17

[2] CHRISTIN, 2006.p. 68.

[3] JAKOBSON, 2004.p. 23.

[4] ALMEIDA, 2000.p. 48.

[5] ALVARES, 1992. p. 84.

[6] MAXAKALI, 2004.

[7] CAMPOS, 1970. p. 26.

[8] CAMPOS, 1970. p. 24.

[9] ZUMTHOR, 1997. p. 81.

[10] RISÉRIO, 1996. p. 93.

[11] PIGNATARI, 1995. p. 161.

[12] PIGNATARI, 1995. p. 162. 
[13] RISÉRIO, 1996. p. 93.

[14] Podemos pensar que, no caso de uma obra oral, tal metade deve ser avaliada em função da performance.

[15] EISENSTEIN, 1994. p. 152.

[16] GÉFIN, 1982. p. 8.

[17] EISENSTEIN, 1994. p. 153.

[18] CARONE NETTO, 1974. p. 15.

[19] MAXAKALI, 2004.p. 8-17.

[20] FREUD, 1995. p. 22.

[21] LEVY-STRAUSS, 1975.

[22] ENCICLOPÈDIA EINAUDI, p. 221.

[23] POPOVICH, 1976b. p. 02.

[24] Ib. 1976. p. 2 .

[25] Ib. p. 3-10.

[26] Ib. p. 2 .

[27] FREUD, 1995. p. 23.

[28] FREUD, 1995. p. 117.

[29] CAMPOS, 1994. p. 82.

[30] CAMPOS, 1994.

[31] PIGNATARI, 1995.

[32] LOUVEL, 2006. p. 218.

[33] FREUD, 1995. p. 118 .

[34] ZUMTHOR, 1997. p. 33.

\section{Bibliografia}

ALMEIDA, Maria Inês. Os índios, seus livros, sua literatura. In: Escola indígena - índios de Minas Gerais recriam a sua educação. Belo Horizonte: Secretaria de Estado da Educação de Minas Gerais. Abr/2000, p. 45-65. (Coleção Lições de Minas, v. VI)

ALVARES, Myriam Martins. Yãmîy, os espíritos do canto - a construção da pessoa na sociedade Maxakali. UNICAMP. Dissertação de mestrado em Antropologia, 1992 . 
ANTUNES, Marisa Aparecida. Pequeno dicionário indígena Maxakali-Português, Português-Maxakali. Juiz de Fora: [s.n.], 1999.

ARBEX, Márcia. (sel. e org.) Poéticas do visível - ensaios sobre a escrita e a imagem. Belo Horizonte: Programa de Pós-Graduação em Letras: Estudos Literários, Faculdade de Letras da UFMG, 2006.

BICALHO, Charles. Yãmîy Maxakali - um gênero nativo de poesia brasileira In: Anais do $X$ Congresso Internacional da Associação Brasileira de Literatura Comparada, ago/2006.

- Mini-dicionário Maxakali-Português, Português-Maxakali. Fruto de uma pesquisa de iniciação científica desenvolvida com bolsa do CNPq durante graduação na FALE/UFMG. 1996/1998.

CAMPOS, Haroldo de. Metalinguagem - ensaios de teoria e crítica literária. 2. ed. Petrópolis: Vozes, 1970.

1994.

(org.) Ideograma: lógica, poesia, linguagem. 3. ed. São Paulo: EDUSP,

CARONE NETto, Modesto. Metáfora e montagem. São Paulo: Perspectiva, 1974.

CHRISTIN, Anne-Marie. A imagem enformada pela escrita. In: ARBEX, Márcia. (sel. e org.) Poéticas do visível - ensaios sobre a escrita e a imagem. Belo Horizonte: Programa de Pós-Graduação em Letras: Estudos Literários, Faculdade de Letras da UFMG, 2006.

Constituição da República Federativa do Brasil. Editada por Antonio De Paulo. 17. ed. Rio de Janeiro, DP\&A, 2004.

EINAUDI, Enciclopédia. Parentesco (v. 20). Tradução: Magda Bigotte de Figueiredo. Imprensa Nacional - Casa da Moeda, 1989.

EISENSTEIN, S. O princípio cinematográfico e o ideograma. In: Ideograma: lógica, poesia, linguagem. CAMPOS, Haroldo de. (org.) 3. ed. São Paulo: EDUSP, 1994. p. 149-66.

FREUD, Sigmund. Obras psicológicas completas de Sigmund Freud. 2. ed. Rio de Janeiro: Imago, 1995.

GÉFIN, Laszlo K. Ideogram - history of a poetic method. Austin: University of Texas, 1982 .

JAKOBSON, Roman. Lingüística, poética, cinema. São Paulo: Perspectiva, 2004. LÉVI-STRAUSS, C. Totemismo hoje. Tradução: Malcolm Bruce Corrie. Petrópolis: Vozes, 1975.

LOUVEL, Liliane. A descrição "pictural" - por uma poética do iconotexto. In: ARBEX, Márcia. (sel. e org.) Poéticas do visivel - ensaios sobre a escrita e a imagem. Belo Horizonte: Programa de Pós-Graduação em Letras: Estudos Literários, Faculdade de Letras da UFMG, 2006.

MAXAKALI. Yãmîy xop xohi yõg tappet/Livro de cantos rituais maxakali. Belo Horizonte: SEE/MG/Brasília: FUNAI, 2004.

PEIRCE, C. S. Semiótica. Tradução: José Teixeira Coelho Neto. 3. ed. São Paulo: Perspectiva, 2005.

PIGNATARI, Décio. Letras, artes, mídia. São Paulo: Globo, 1995. 
Txt: Leituras Transdisciplinares de Telas e Textos, Belo Horizonte, v.3, n.6, p.36-51, 2007

Curitiba: Travessa dos Editores, 2005

PopoVICH, Harold. Maxakali supernaturalism. Comunicação ao Summer Institute of Linguistics, 1976a (mimeo).

- Maxakali myths on cultural distinctions and Maxakali sense of inferiority to the national brasilian culture.summer Institute of Linguistics, 1976b (mimeo).

RISÉRIO, Antônio. Oriki orixá. São Paulo: Perspectiva, 1996.

ZUMTHOR, Paul. Introdução à poesia oral. Tradução de Jerusa Pires Ferreira, Maria L. Diniz Pochat e Maria Inês de Almeida. São Paulo: Hucitec, 1997. 